\title{
Poética de una infancia: Juego, nostalgia y soledad habitada en "Jamil" de Álvaro Mutis*
}

Fecha de recepción: 19 de septiembre de 2014

Fecha de aprobación: 04 de marzo de 2015

\section{Resumen}

En el presente artículo se hace un seguimiento a la novela "Jamil" que aparece en Tríptico de mar y tierra (1993) y a la vida empantanada por la errancia, la pérdida y el fracaso de Maqroll el Gaviero, personaje memorable de la poética mutisiana, en una de sus últimas aventuras como marinero en tierra firme. Las empresas que asume Maqroll son parte de su vida, de su presente en la tierra firme que ha adoptado como hogar y han dejado una huella indeleble en lo más profundo de su existencia. Pero, ¿qué sucede cuando los senderos del infortunio se ven atenazados por la renuncia a esa vida vagabunda llena de secretos dolores que se comunican solamente a la soledad? Las empresas y tribulaciones del Gaviero se interrumpen con la llegada de un personaje que hace posible que se piense que todo lo vivido no fue solamente un trabajo perdido. Estamos hablando, pues, de Jamil el hijo de Abdul Bashur.

Palabras clave: Maqroll, Jamil, infancia, nostalgia, juego, soledad habitada.

*Artículo de reflexión.

Citar: Ayram Chede, C.J. (julio-diciembre de 2015). Poética de una infancia: Juego, nostalgia y soledad habitada en "Jamil" de Álvaro Mutis. La palabra, (27), 67-77.
Carlos Julio Ayram Chede Universidad de los Andes carlosayramchede@gmail.com

Licenciado en Lengua Castellana de la Universidad del Tolima. Estudiante de último semestre de la Maestría en Literatura de la Universidad de los Andes. 


\section{Poetics of childhood: play, nostalgia and inhabited solitude in "Jamil" by Álvaro Mutis}

Abstract

The present article articulates the relation between the novel "Jamil", which is part of the Triptico de mar y tierra [Land and sea tryptic] (1993); and the life of "Maqroll el Gaviero", that memorable character of the poetics of Álvaro Mutis flooded by wandering, loss and failure, in one of his last adventures as a sailor on terra firma. The adventures lived by Macqroll are part of his life, of his present on the mainland which he has adopted as a home, and have left an indelible print on the deepest part of his existence. But, what happens when the paths of misfortune are threatened by the abandonment of that vagabond life full of secret pain that is only communicated to solitude? The adventures and meditations of the Gaviero are interrumpted by the arrival of a character that enables him to think that all that has been lived is not just loss. We are speaking of Jamil, the son of Abdul Bashur.

Key words: Maqroll, Jamil, childhood, nostalga, play, inhabited solitude.

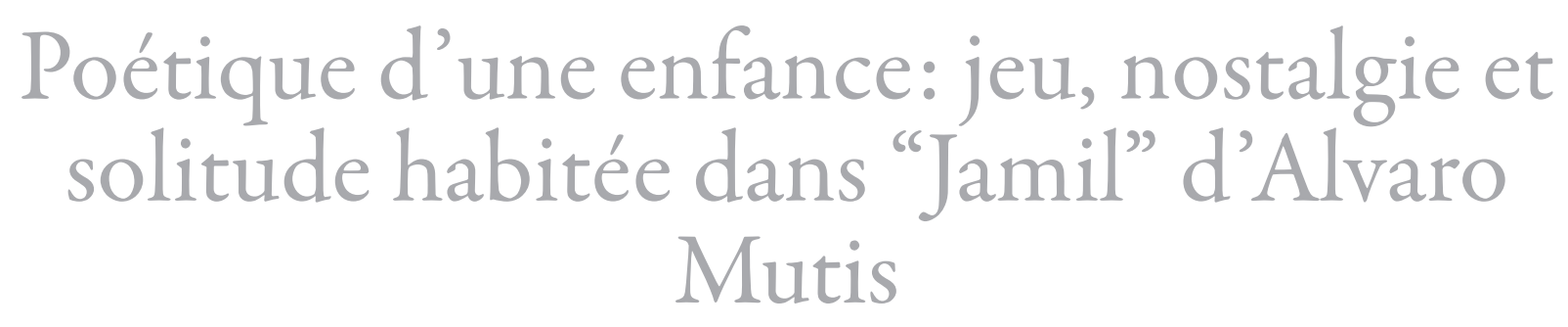

\section{Résumé}

Cet article a pour but d'analyser le roman «Jamil » présent dans Triptico de mary tierra [Triptyque mer et terre].(1993). Nous nous pencherons sur des thématiques telles que la vie inondée par l'errance, la perte et l'échec dans une des dernières aventures en tant que marin sur terre de Maqroll el Gaviero, personnage mémorable de la poétique d'Alvaro Mutis. Les entreprises de Maqroll font partie de sa vie, de son présent sur la terre ferme qu'il a adoptée comme foyer. Celles-ci ont laissé une empreinte indélébile au plus profond de son existence. Mais, qu'arrive-t-il lorsque les sentiers du malheur sont effacés par l'abandon de cette vie vagabonde, pleine de douleurs secrètes qui ne débouchent que sur la solitude ? Les aventures de Gaviero sont interrompues par l'arrivée de Jamil (le fils d'Abdul Bashur) qui lui montre que tout ce qui a été vécu n'est pas perdu.

Mots clés : Maqroll, Jamil, enfance, nostalgie, jeu, solitude habitée. 
En las errancias de Maqroll el Gaviero se descubre un camino infestado de empresas fallidas y pesadumbres irremediables. El Gaviero ha errado por parajes que le han ofrecido, de manera seductora aventuras y riesgos que terminan siendo simulacros de las grandes hazañas de los héroes épicos y fracasos que se van acumulando en una vida que no pertenece a ningún lugar, que niega toda orilla. Las empresas de Maqroll son una búsqueda de lo imposible o de lo incierto y son de por sí una sentencia incuestionable tanto de un fracaso como de una pérdida sin remedio alguno; viaja por el Xurandó buscando los aserraderos y la Nieve del Almirante con Flor Estévez se pierden para siempre; el famoso prostíbulo de Villa Rosa signa la trágica muerte de Ilona Grabowska por culpa de Larissa; el falso proyecto del ferrocarril, en el cual estuvo involucrado, hace que pierda a Amparo María y la plácida estancia en los recuerdos de una tierra caliente. Maqroll es, sin dudas, un desafortunado, un marinero cuyos errores lo han anclado en tierra firme.

Cuando Maqroll se ha retirado a Pollensa, en la isla de Mallorca en España, acontece en su vida algo que es diferente a las experiencias transitadas, suceso que es recuperado por esa misteriosa voz que nos ha introducido en sus errancias, la cual manifiesta que este encuentro "[f] ue una experiencia por entero inusitada y cargada de sorpresas que vinieron a revelarle [a Maqroll] un rincón hasta entonces virgen de su vida sentimental" (Mutis, 2007, p. 703). Cuando el Gaviero se ha instalado de nuevo en comunión con la soledad, llega inesperadamente un niño, - Jamil, el hijo de su entrañable amigo Abdul Bashur- a poblar una existencia que se resiste al vagabundeo $y$, con un poder insospechado, ilumina regiones del alma que tal vez pensaba este marinero en tierra que ya habían quedado envueltas en la obscuridad de sus propias pérdidas.

La historia que confecciona la voz que le ha seguido los pasos a Maqroll desde antes de su expedición por el río Xurandó ${ }^{1}$, podría afirmarse, cierra un ciclo en la vida del Gaviero y deja un cambio en la concepción que este tiene de la vida y del mundo. La voz de Maqroll hace explicito su cambio de esta manera:

En esa forma comenzó para mí una nueva vida, habitada cada hora del día y de la noche por esa criatura que iba descubriendo el mundo llevado de mi mano, a tiempo que me daba una lección que creía aprendida por mí para siempre. Era, en cierta forma, como volver al arcano diálogo con los oráculos (p.751).

El relato sobre Jamil no es más que un doble pretexto: de un lado, sigue ardiendo la pretensión por recoger los más íntimos y dispersos detalles sobre la errancia de Maqroll, esta vez, para conocer la sustancia de la que está hecha una aventura diferente a las demás: "preferí, en cambio, intentar transcribir las palabras mismas con las cuales Maqroll nos contó su experiencia. En ellas, que anoté de inmediato después de escucharlas, se esconde todo el sordo dolor que le costó ese trance (...)” (p. 703). De otro lado, está esa intención de seguir escarbando en el hombre, en su intimidad, en su universo y, sobre todo, en esos cambios que germinan cuando el Gaviero ha conocido a Jamil: "no había duda, Jamil había sido la trampa que esperaba nuestro amigo, escondida en el intrincado laberinto de su irremediable odisea" (p. 774).

La manera como conocemos el relato que transcribe esa voz

1 Antes de la saga de Las empresas y tribulaciones de Maqroll el Gaviero, Maqroll es ya un personaje que aparece en poemarios como Los elementos del desastre (1953), Los trabajos perdidos (1965) y Reseña de los hospitales de ultramar (1973), publicados posteriormente en Summa de Maqroll el Gaviero 1948-1988, recogido luego en una edición del Fondo de Cultura Económica en 1990. 
introductora nos invita a otro viaje más, otro periplo en la vida del ojo avizor, que al presente, solo otea barcos chatarra y que ha sentido el peso de la convivencia con un niño que es claramente lo inesperado, lo imprevisto, lo espontáneo. El relato que nos cuenta Maqroll, por la mediación de esa voz - que es su narrador oficial- puede leerse en clave de una posible poética que alude a una infancia que llega a la vida del Gaviero, pero también que se reconquista y se vuelve a imaginar una vez se sabe que no está expulsada de la vida del hombre, solo que está ahí esperando a ser otra vez advertida, vivida $y$ confrontada con la memoria. Bachelard (2011) afirma: "la memoria es un campo de ruinas psicológicas, un revoltijo de recuerdos. Toda nuestra infancia debe ser imaginada de nuevo. Al reimaginarla tendremos la suerte de volver a encontrarla en la propia vida de las ensoñaciones de niño solitario" (p. 151).

Es preciso advertir que esa poética de la infancia habla de Jamil pero al tiempo habla de Maqroll, habla del niño que es Jamil y del niño que va descubriendo el Gaviero. Es una oda al tiempo de la imaginación, a la fantasía y sus reglas posibles e inexactas. En la narración del encuentro con el hijo de Abdul Bashur se descubre el juego como potencia organizadora de un mundo íntimo y poblado de la historia inventada y posible, del juego como acto inagotable, vital y necesario. Pero también se encuentra la imperdonable nostalgia que los lleva a un pasado hecho de preguntas y a un futuro que se esquiva porque es más certero que la historia que se ha vivido. Por último, está esa soledad que ha dejado de estar desprovista de alguien, ha sido habitada en un doble sentido: a la llegada de Jamil a la vida del Gaviero y después cuando Jamil se ha marchadolos entrañables recuerdos de su vida con el niño, que nítidos se dibujarán para siempre en su memoria.

\section{El juego: fantasías e} historias

Jamil Bashur aparece para transformar la vida de Maqroll. Jamil tiene casi los mismos gestos de Abdul, lo que le permite estrechar una relación muy particular con el Gaviero y un pacto que solo los dos entienden a la luz de la historia en común que los envuelve: las correrías y empresas de Maqroll y el padre del niño. Ellos han creado un círculo de amistad donde han fundado un universo que desdibuja la imagen del cuidador y el cuidado, del sustituto y el huérfano, del adulto y el niño. Jamil y el Gaviero han hecho de su relación un acto de plena reciprocidad.

Lina, la madre de Jamil, le ha encargado a Maqroll que cuide de su hijo, quelo proteja mientras su trabajo en Alemania termina. A pesar de las dimensiones del encargo y la protección, que son dos constantes en la narración sobre Jamil, el Gaviero asume que el niño es una compañía de potencias salvadoras que lo llevan de la mano a contemplar el gran espectáculo que es la vida y la condición humana. La compañía que significa Jamil, más allá de convertirse en un encargo o en un lastre, se convierte en una oportunidad para que Maqroll se interrogue sobre zonas de su existencia que pensaba estaban claudicadas: "su compañía durante un año largo tuvo para mí esa virtud salvadora y sí no me ha convertido en otro hombre, sí, al menos, me ha llevado a ser un resignado espectador de nuestra batalla con las sombras" (Mutis, 2007, p. 757).

La aceptación que Maqroll tiene por el ingreso de Jamil a su vida pierde su matiz de aprobación para convertirse en un acto de plena consciencia por el acceso al mundo que es la infancia; deja de ser una etapa de la vida y se constituye como una condición de existencia y entendimiento del mundo. Maqroll se adentra en el amplio, fantástico e infatigable universo de la infancia con Jamil y, éste a su vez, quiere saberse de un mundo que habitan los adultos para comprender sus lógicas. La 
novedad es un acontecimiento en la vida de los dos: el Gaviero va develando lo que hay en las entrañas más profundas de ese niño y ese niño va descubriendo una vida que por herencia y experiencia le pertenece. Así lo expresa Maqroll en su relato:

La razón estaba en Jamil, en mí descubrimiento de Jamil y en su inagotable ansiedad por abarcarlo todo, por saberlo todo y por verlo todo. Me temo que los estoy aburriendo soberanamente con este insistir en la novedad de mi experiencia que para ustedes ha de ser algo familiar. Deben, de seguro, hallar un tanto necio el toparse con alguien para quien la relación con una criatura que no ha cumplido los cinco años se convierte en una experiencia reveladora (p. 738).

Una vez que Jamil ha entrado en Pollensa y es llevado al lugar que habita Maqroll, inmediatamente hay unas reglas que empiezan a dirigir esa nueva vida y que obedecen a un juego. Siguiendo a Roger Caillois “[n] o cabe duda que el juego se debe definir como una actividad libre y voluntaria, como fuente de alegría y diversión" (Caillois, 1986, p. 31), es mas el juego se va creando en las actividades diarias del niño y el Gaviero. No obstante, no puede ser un juego determinado, convencional, usado, agotado, acabado, jugado por otros. Es el juego de los dos. ¿En qué consiste? En una reinvención permanente, en un movimiento absoluto: salir a pescar, capturar objetos encontrados en el mar, ficcionar historias sobre piratas, precisar historias para cada objeto encontrado en la isla, insistir en la aventura; todo esto resulta un juego que Jamil propone a Maqroll y que el Gaviero le propone al niño y que los lleva a descubrir las secretas leyes que rigen el universo de la infancia.

El juego no es un tiempo relacionado con el desperdicio o que se emplea para disfrutar o habitar el ocio, representa la vida que empiezan a construir Maqroll y Jamil. Johan Huizinga (1972) ve que el juego "traspasa los límites de la ocupación puramente biológica o física. Es una función llena de sentido. En el juego «entra en juego» algo que rebasa el instinto inmediato de conservación y que da un sentido a la ocupación vital" (p. 12). Por lo anterior, se podría rastrear una posibilidad que se contempla en ese juego de la vida entre el Gaviero y el niño Bashur: entender el mundo del otro, entender qué leyes gobiernan ese universo que los dos han habitado el uno por errante y marino, el otro por ser un niño. Maqroll se adentra en la infancia, en esa patria del hombre y para ello acude a hacerle vivir a Jamil aventuras similares a las vividas por él y Abdul cuando recorrían su vida en los Tramp Steamer ${ }^{2}$; las salidas a pescar se convierten, en este caso, en la gran odisea que Maqroll propicia para Jamil y que son el tiempo ocupado por los dos, el tiempo vital: "la pesca en el muelle se convirtió en nuestra principal actividad. Otros pescados vinieron, (...) había que ver con qué aire ufano nos miraba Jamil en la mesa cuando uno de aquéllos, sacado por él, era el plato principal en casa de Mosén Ferrán” (Mutis, 2007, p. 750).

Pero las dimensiones de ese juego pueden entenderse a la luz de una intención pedagógica. No solo se favorece el encuentro con la experiencia, en este caso de la pesca y la navegación, sino que se abre un portal que lleva a Jamil, de un lado, a descubrir cómo funciona el mundo que le revela Maqroll. Por su parte, para el Gaviero se va potenciando esa capacidad de asombro por las leyes que rigen la infancia y que luego va acogiendo como necesidad para existir. En síntesis, el juego es una cuestión de aprendizaje:

Me lancé, luego, a una larga explicación de cómo se

2 Barcos pesqueros. 
hacía esa pesca y le conté que había sido dueño de un pesquero junto con un marino noruego años atrás. Jamil me miraba entre escéptico y en eso un pez comenzó a jalar de su anzuelo. Le ayudé a jalar el anzuelo. Le ayudé a recoger el hilo girando el carrete mientras él sostenía la caña con las dos manos. Le brillaban los ojos de satisfacción y pronunciaba en árabe exclamaciones de alegría. La presa resultó ser un pescado de casi tres kilos. No supe decirle de qué especie se trataba, lo cual no ayudó mucho a consolidar mi prestigio como pescador (Mutis, 2007, p. 749).

Pero el juego se no agota, por el contrario, descubre otras posibilidades para prolongar el tiempo de la infancia y el tiempo de la imaginación y de la fantasía. Las aventuras y campañas de exploración que Maqroll y Jamil emprenden anulan el peso de un tiempo que gobierna la inevitable cita que tendrán luego con la separación; ese tiempo cronológico se incendia y se consume lejos del tiempo que el Gaviero y el niño Bashur fundan para constituir un lugar propio en Pollensa. En respuesta a ese tiempo que corre, el tiempo de la aventura y la fantasía se materializa, se hace palabra, realidad e historia. Cada campaña de exploración se convierte en una oportunidad para Jamil de encontrar objetos que otros han perdido, llevarlos al refugio de Maqroll, signarlos con las reglas de la fantasía, hacerlos suyos y de su imaginación en tanto que es un descubrimiento que comparte con el Gaviero:

Mi refugio se fue llenando de los objetos más inesperados que, una vez escogidos y guardados por Jamil, adquirían un matiz evocador y mágico. Caracoles de todas las formas y tamaños, botellas y trozos de madera abandonada por el mar en la playa, esqueletos de aves y peces descubiertos en las cavidades de los acantilados, trozos de cuerda y retazos de velamen, objetos metálicos imposibles de reconocer y hasta letras clavadas en tablas descoloridas. Cada uno de estos objetos le servía a Jamil para construir una historia que les daba presencia y validez indiscutible (Mutis, 2007, p. 751).

Otro rostro de ese juego se precisa cuando la capacidad para inventar se hace explícita, necesaria y potente para combatir ese otro tiempo del cual poco se habla pero del que se tiene una certeza inexorable: "la imaginación del niño no vive de esas fábulas fósiles, de esos fósiles de fábulas, sino de sus propias fábulas, que no le cuenta a nadie, en su propia ensoñación. Entonces la fábula es la vida misma" (Bachelard,
2000, p. 180). El contar una historia para cada objeto encontrado puede leerse en una doble necesidad: En primer lugar, hacer de lo encontrado un hecho fabuloso, es decir, portador de una historia, de una ficción capaz de hacerse tierra, memoria y experiencia en la vida que Jamil comparte con Maqroll. En segundo lugar, es evidente una necesidad de seguir confiriéndole al lugar de residencia una historia que desazona a la lógica y la razón, lo cual significa, seguir haciendo que ese lugar obedezca a la naturaleza de la mentira, en este caso, de las bellas e inocentes mentiras que se tejen sobre los objetos.

La relación que Jamil establece con los objetos que encuentra -y en los cuales inscribe una historia inventada- se convierte en un acontecimiento en el mundo de Maqroll; es, por tanto, una manera de incrementar esa capacidad de asombrarse por ese otro que ha llegado a su vida y, que con los sordos poderes de la fantasía y el ingenio, ha dejado abierta la puerta al reino de la infancia. "Entonces un objeto puede ser un polo de una meditación del universo. Así, como dicen los filósofos, cada objeto puede ser una apertura al mundo. Como dice Jacques Brosse, cada ser del mundo puede darnos una introducción al mundo" (Bachelard, 2000, p. 189). 
Es preciso advertir que la invención de las historias no sólo se hace como en una especie de palimpsesto en los objetos que encuentra Jamil en sus correrías con Maqroll. Hay también una capacidad de jugar, en el caso del niño, con las historias que son ya un suceso en el mundo, por ejemplo, la de los corsarios y los piratas. El juego comienza cuando no se conoce con exactitud el hecho, pero esto no se convierte en obstáculo para no saber de ella. Sobre esa otra historia, lejana al mundo de la infancia, la ficción se hace indispensable para decir algo sobre ella, sencillamente para completarla en tanto la imaginación se hace palabra y complemento de la misma. Pero el juego no solo consiste en inventar la historia, el juego también afecta a Maqroll, lo afecta en lo que sabe. Le sorprende la inventiva de ese otro, los poderes de decirlo todo sin albergar el lugar para la verdad.

El Gaviero ha descubierto cómo una nueva empresa al lado de Jamil emerge, sin posibilidad alguna de resistencia. Como el juego es la vida -y para no caer en las redes de la mera simulación-, Caillois define que "la finalidad del juego es el juego mismo" (Caillois, 1986, p. 276). Por consiguiente, se podría pensar que el juego es útil, provechoso y fuente de aprendizaje, es decir, es una actividad útil para la vida y la existencia. De verdad se pesca, se hacen campañas de exploración, se habla sobre los piratas y se juega a ser parte de una vida en sus más anchas dimensiones y potencias.

Maqroll quiere enseñarle a Jamil -por ser este hijo de su entrañable amigo Abdul Bashur- las secretas reglas de ese universo que está en el mar, en la pesca, en la vida flotante del marino. A su vez, el niño le da una gran lección de vida al Gaviero permitiéndole escrutar en sus más hondos abismos a aquél niño que todavía no se ha ido, aún no se ha evaporado y que todavía preserva para, en algún momento, salvarse de sí mismo y, por qué no decirlo, del mundo. "Mi complicidad llegó a ser tan absoluta -al igual que lo fue con su padre- y llegamos pronto a no necesitar explicar la razón de nuestros actos emprendidos siempre de consumo dentro de un ámbito sólo por nosotros conocido" (Mutis, 2007, p. 752).

En ese sentido, esta nueva empresa que tiene Maqroll en su vida lo lleva, como en su expedición por el Xurandó, a devolverse a su ser, a su existencia lo que piensa sobre la infancia y su poder. El Gaviero ha descubierto potencias de la infancia que lo ha contorsionado que lo ha vuelto otro sin perder esa imagen que tiene de sí mismo y lo han vuelto a llevar por el camino de la pregunta por su vida y por su errancia, sólo que esta vez esa errancia se encuentra en el corazón: “con frecuencia es en el corazón del ser donde el ser es errabundo. A veces es fuera de sí donde el ser experimenta consistencias. A veces también está, podríamos decir, encerrado en el exterior" (Bachelard, 2000, p. 188).

\section{Nostalgia y soledad habitada}

El juego ha llevado a Maqroll y a Jamil por el sendero del encuentro, esto los lleva a fundar un lugar para vivir en Pollensa. No obstante, en medio de esa vida que comparten los dos, la imprescindible nostalgia, esa que persigue al Gaviero desde años atrás, se instala nuevamente en su vida y también anida en Jamil Bashur que, a pesar de ser un niño, sufre por una especie de no-origen que siente como un poder genitor en esa vida que construye al lado de Maqroll. Según Milan Kundera en la novela La ignorancia "En griego, «regreso» se dice nostos. Algos significa «sufrimiento». La nostalgia es, pues, el sufrimiento causado por el deseo incumplido de regresar" (Kundera, 2000, p. 5). La nostalgia la sufren, más que por un lugar físico y concreto al cual están atados, a una historia que está tejida en el pasado de ambos. Los dos compañeros, han vuelto a mirar el pasado, cada uno a su 
manera para encontrarse con las preguntas dejadas para ellos. Ambos se han tornado en una actitud de nostalgia que les permitirá regresar a lo vivido para comprender el inmenso presente que se apodera de los dos.

Maqroll cuenta su relato a Mosén Ferrán, a la voz introductora y su esposa. Teje en su palabra lo que esperaríamos que fuera su última empresa. Narra con profunda congoja y nostalgia; hay un inminente sufrimiento porque Jamil ha regresado con su madre, porque ha partido y lo ha dejado solo. El Gaviero se ha transformado; su vida ha quedado perpleja ante la visita inesperada del hijo de Bashur y esto le ha permitido barajar otras posibilidades de su vida que aún no había contemplado. En todo caso, esa nostalgia que lo devora lo ha devuelto al paraíso perdido de la infancia.

Pero no sólo la actitud de extrañar y sufrir por ese otro que fue su complemento es lo que delata que Maqroll es un ser nostálgico. También lo es su actitud hacia Jamil, actitud que lee en clave del recuerdo y el extrañamiento. El niño es como ver a Abdul, saberlo en ese cuerpo pequeño es intuir su presencia en los gestos que ha heredado de él. Jamil no es una derivación de Abdul, no es su alter ego ni su figura reencarnada, es otro ser que porta una historia que sabe muy bien el Gaviero. Hay un profundo pacto con el recuerdo y la memoria al contemplar al niño, porque este lo devuelve a Abdul, porque ese le hace recordar a aquél soñador de navíos que tanto lo acompañó en algunas de sus empresas desafortunadas. Maqroll describe a Jamil de esta forma:

A menudo tenía que hacer un gran esfuerzo mental para darme cuenta de que se trataba de un niño que iba a cumplir cinco años y no un adulto de casi cuarenta, que era la edad de Abdul cuando nos conocimos en El Cairo. El paralelismo se acentuaba por obra de algunos gestos de Jamil, que, como les dije, recordaban a los de su padre. Un forma de levantar el brazo y mantenerlo en alto mientras iniciaba una frase que deseaba subrayar, los movimientos de las manos en desacuerdo con las palabras que pronunciaba, hasta dar la impresión que alguien, allá escondido dentro de ellos, ordenaba esos gestos con un propósito oculto, y finalmente, el hábito de dejar ciertas frases sin concluir y quedarse un momento callado (Mutis, 2007, p. 752).

El Gaviero ve a Jamil y contempla de nuevo a Abdul y sabe que hay algo que los distingue, que los diferencia, que son padre e hijo pero que no son iguales a pesar de compartir rasgos idénticos. Maqroll reconoce a Abduly a Jamil como seres iguales en su diferencia, a seres que complementan, de manera diferente, estados del alma y la existencia; son seres de la compañía y la amistad recíproca. De cualquier modo, es con Jamil con quien Maqroll logra recorrer senderos del pensamiento que tal vez no había contemplado en su inmortalidad. Es con Jamil y no con Abdul. Su amigo, el soñador del Tramp Steamer ideal, solo es parte de su memoria, de esa que es un territorio de nostalgias, desesperanzas y pérdidas.

¿Y de Jamil? ¿Se podría decir que es un nostálgico también? Los recuerdos de Jamil no pertenecen al orden de lo vivido, como en el caso del Gaviero, pareciera que estuvieran determinados por una especie de no-origen. El niño Bashur -que apenas cuenta con cinco añoses portador de una historia que lo antecede, estamos hablando en este caso de la historia de su padre. Jamil guarda un difuso recuerdo de las visitas de Abdul lo cual imposibilita que este se comunique con él a través de una memoria capturada por la experiencia propia. En cambio, lo que sucede es una apropiación de su padre a través de las historias que le proporciona 
Lina Vicente, de las historias que escucha de boca de Maqroll, de esos testimonios mediados que le permiten conocer el incumplido sueño de un navío perfecto para su padre.

Jamil experimenta una nostalgia diferente a la de Maqroll pero sigue conservando esa intención de añoranza y apego por un pasado que no le correspondió vivir pero que construye con los fragmentos de una memoria que es de otros y que poco a poco empieza a descansar en su poder. Jamil quiere ingresar en la vida que aconteció antes de él, quiere saberse parte de una historia que lo exilió con la muerte de Abdul. Para esa tarea de vivir confeccionado un telar de historias previas a su existencia, el Gaviero acude a la narración, esa imprescindible palabra que se torna relato para entregar un legado que él carga con la emoción y la experiencia de sus años en compañía de Abdul por mares, puertos y tierra firme.

Lina Vicente es extrañada también por Jamil. La actitud nostálgica intenta ser muy discreta aunque Maqroll sí advierte cómo el niño ha empezado a recordar a su madre. Para no turbar esa vida donde se saben juntos y en situación de aventura, él prefiere no comunicarle al Gaviero su estado de extrañamiento que tiene hacia Lina. Así lo recuerda
Maqroll en su relato:

Durante los últimos meses de su estadía en Pollensa, Jamil parecía extremar sus cuidados conmigo. No sabía cómo expresar su afecto y no lograba conciliar el deseo de ver a su madre y su curiosidad por lo que le esperaba, con el apego que sentía por mí y por la vida vivida a mi lado (Mutis, 2007, p. 766).

Así, Jamil no puede huir de esa condición nostálgica que lo acecha, para ello la enfrenta a su manera, en medio de sus tiempos, de sus juegos, sus historias y ávidos de un presente que también tiene el inconfundible rostro del pasado.

¿Qué sucede cuando la soledad que tanto ha buscado Maqroll se ve habitada por la compañía de un otro? Las errancias de Maqroll, contadas por esa misteriosa voz introductora ha visto cómo en la crudeza de la soledad "conoció el Gaviero el miedo de sus miserias más secretas, el pavor de un gran vacío que le acechaba tras sus años llenos de historias y paisajes" (Mutis, 2008, p. 149). Esa voz introductora nos cuenta momentos de sustracción del Gaviero a parajes solitarios, alejados de todo, de todos, lugares donde realmente se siente solo, despojado de la presencia de un alguien. Lugares que busca e implora que estén solos que como lo advierte Octavio Paz "la soledad es el fondo último de la condición humana, el hombre es el único ser que se siente solo y el único que es búsqueda de otro" (Paz, 2012, p. 211); y esa búsqueda de otro, no es más que la búsqueda de sí mismo, del cosmos íntimo y propio que se va develando en una pugna claramente existencial.

Con todo, Maqroll no tiene posibilidad alguna ahora de encontrar a otro, que es él mismo en la soledad, es decir, su doble. Ya no está presente esa definición de soledad que da, por ejemplo, Juan Rulfo "al afirmar que la soledad es una cosa que se llega a querer del mismo modo como se quiere a una persona" (Rulfo, 2012, p. 82). No, ya la soledad no es otra persona más que convive con el Gaviero, porque ese otro, que presuntamente debería emerger en contacto con la soledad, se ha materializado, se ha vuelto carne, presencia y mirada. Maqroll ahora recibe a Jamil en la soledad del lugar que habita en Pollensa, recibe al niño, al ser, al otro, a su compañía por más de un año. En consecuencia, se podría afirmar que ese ambiente de soledad que intentó buscar el Gaviero retirándose a vivir a Mallorca se ve ocupado por la presencia de ese niño del cual ha prometido cuidar; su soledad se ha convertido en una soledad habitada. 
La manera como esa soledad está habitada se puede rastrear en varios aspectos. Primero, en la manera como se ve invadida de las historias que albergan los objetos que recoge Jamil en sus campañas de exploración. Segundo, en las preguntas que Jamil constantemente está pescando en ese mar de inquietudes que lo acechan y que le hace directamente a Maqroll. Tercero, en la historia que el Gaviero le cuenta al niño sobre las proezas de él y su padre. Cuarto, en la compañía que representa el hijo de Abdul, compañía que está determinada por su inocencia y genialidad.

Hay otra forma de esa soledad habitada que es posterior a la partida de Jamil de la vida del Gaviero. Cuando Lina Vicente vuelve a Pollensa por su hijo, éste en una ceremonia íntima y necesaria se deshace de todos los objetos que ha encontrado en sus viajes con Maqroll. Jamil empieza con una despedida que es necesaria y justa: "bien saben ustedes que no existen palabras para describir lo que en una ocasión como ésa sucede dentro de nosotros. Era la despedida de Jamil. La que debía suceder entre los dos, sin testigos, ni adioses de última hora" (Mutis, 2007, p. 771). Los dos sabían, en lo más hondo de su ser, que la separación era la única cita ineludible, que esta llegaría y los enfrentaría a un adiós, pero a un adiós diferente, a la manera de los compañeros de viaje.

Una vez que Jamil se ha marchado Maqroll siente el peso del abandono. El vacío es evidente en su narración. El niño se ha ido definitivamente. Se podría pensar que el Gaviero volvería a su estado de soledad pura, de encuentro con ese otro que es su doble, que es el producto de su vida. Pero no, no hay soledad pura de nuevo, hay soledad habitada, porque la interferencia de los recuerdos, de la experiencia es de ahora en adelante inevitable y se ha constituido como acontecimiento en ese universo maqrolliano.

Para finalizar, el cierre que hace este último relato de la vida del Gaviero nos deja con una doble sensación. En primer lugar, el sentimiento de pérdida que en otros momentos Maqroll experimenta esta vez tiene un anverso y un reverso. Su anverso es la despedida y la partida de Jamil; su reverso es que no es la pérdida de esa vida que fue cercana como en el caso de Ilona, Abdul o Amparo María y que desaparece para siempre de la faz de la tierra, aquí la pérdida es un acto simbólico; perder a Jamil es descubrir que se ha extraviado su compañía pero que al tiempo ha descubierto la necesidad de preservar al niño que lleva consigo.

En segundo lugar, se puede interpretar que Maqroll le da la bienvenida a la tierra firme, ese lugar que puede que, de ahora en adelante, se convierta en el lugar de las consistencias de su propio ser: "este cambio ha bastado para aceptar mi destino y quedarme en Pollensa, marginado y tranquilo, sin intentar nuevos lances que en pasado hicieron de mi vida una delirante secuencia de infortunios" (Mutis, 2007: p. 756). Con "Jamil" se cierran las Empresas y tribulaciones de Maqroll el Gaviero, y con este relato, asistimos por primera vez a la ausencia de la empresa desafortunada y a las tribulaciones por un fracaso conocido de antemano. La pérdida, en este caso, es el mayor éxito que Maqroll ha tenido en los tránsitos desventurados de su vida. Jamil es su puerta a ese paraíso perdido que es la infancia. 


\section{Referencias}

Bachelard, G. (2000). La poética del espacio. Argentina: Fondo de cultura económica.

Bachelard, G. (2005). El derecho de soñar. México: Fondo de cultura económica.

Bachelard, G. (2011). La poética de la ensoñación. México: Fondo de cultura económica.

Caillois, R. (1986). Los juegos y los hombres. México: Fondo de cultura económica.

Huizinga, J. (1972). Homo ludens. Madrid: Alianza Editorial

Kundera, M. (2000). La ignorancia. Barcelona: Tusquets editores.

Mutis, Á. (2007). Empresas y tribulaciones de Maqroll el Gaviero. Colombia: Alfaguara.

Mutis, Á. (2008). Summa de Maqroll el Gaviero. Poesía reunida 1943-2003. Colombia: Alfaguara.

Paz, O. (2012). El laberinto de la soledad. México: Fondo de cultura económica.

Rulfo, J. (2012). Cartas a Clara. México: Editorial RM. 